\title{
Technologies of Suspicion: Coercion and Compassion in Post-disciplinary Surveillance Regimes
}

\author{
Nancy D. Campbell1
}

\begin{abstract}
Drug-use surveillance systems appear in this paper as symptomatic "technologies of suspicion" that constitute a set of empirical modes for producing and interpreting "data" or test results in ways that conflate prediction with prescription, acting as technological forms of supervision, monitoring, supposed deterrence, and ultimately control. Technologies of suspicion are predicated upon a framework of trust; they are deployed within a "system of takings-for-granted" that presupposes trust and thus makes distrust possible. Drug-testing provides an excellent example of the institutionalization of distrust through the deployment of technologies of suspicion not only within institutions but beyond their real and virtual walls. The paper considers the also considers the decentralization and deinstitutionalization of distrust, the capillary dispersion of suspicion throughout the carceral society, and the role of distrust in underwriting the development of certain kinds of knowledge systems and technologies, forms of social and cognitive order, and the functional dispersion of police practices to individuals such as parents, teachers, and peers. Studying why bio-surveillance modalities should diffuse despite their unreliability and their contribution to a generalized climate of suspicion enables the characterization of certain features of the post-sovereign subject in a post-disciplinary regime.
\end{abstract}

\section{Introduction}

Technologies of suspicion constitute a social order that contrasts starkly to what Steven Shapin has called the "great civility" at the heart of western science (1994: 36). "Trust builds social and cognitive order; trust is unimaginable in the absence of such order; yet it also proceeds by way of working knowledge of the state of that order at any time" (Shapin, 1994: 27). On the basis of the working knowledge through which we understand the "distribution of power in the social world," we participate in social routines that produce and distribute trust, defined as the "generalized expectation that the other will handle his freedom" (Shapin, 1994: 39). Where "the other" is considered to fall short of handling his [sic] freedom or acts beyond social norms that circumscribe it, we call into question not only his or her veracity in the moment, but his or her capacity to handle future freedoms in ways that conform to prevailing expectations. Drug-use

${ }^{1}$ Department of Science and Technology Studies, Rensselaer Polytechnic Institute mailto:campbell@ rpi.edu 
surveillance systems are symptomatic "technologies of suspicion." They constitute a set of empirical modes for producing and interpreting "data"-results-in ways that conflate prediction with prescription, acting as technological forms of supervision, monitoring, supposed deterrence, and ultimately control. Shall we trust or distrust these technologies?

"Distrust," Shapin writes, "is something that takes place on the margins of trusting systems" (19). Technologies of suspicion are predicated upon a framework of trust; they are deployed within a "system of takings-for-granted" that presupposes trust and thus makes distrust possible. Drugtesting provides an excellent example of the institutionalization of distrust through the deployment of technologies of suspicion not only within institutions but beyond their real and virtual walls. More important than the institutionalization of distrust, I would argue, is the decentralization and deinstitutionalization of distrust, the capillary dispersion of distrust and suspicion throughout the carceral society, and the role of distrust in underwriting the development of certain kinds of knowledge systems and technologies, forms of social and cognitive order, and the functional dispersion of police practices to individuals such as parents, teachers, and peers. The increasingly common marketing of drug-testing kits to parents pushed me to inquire further into technologies of suspicion (Campbell 2002). Studying why such technologies should diffuse despite their unreliability - and their contribution to a generalized climate of suspicion--enables us to characterize certain features of the post-sovereign subject in a post-disciplinary regime.

Bio-surveillance modalities, which rely upon continuous monitoring of bodily or biological processes, have emerged as defining characteristics of post-disciplinary social control. Proponents of these technologies seek wider markets for their wares, contributing to a generalized climate of suspicion and the increased formation of "working schemes" based on distrust not only between employers and employees but between parents and children, nurses and patients, teachers and students. The widespread availability of these technological artifacts may well encourage the formation of regimes of "coercive compassion" such as the Medical University of South Carolina (MUSC) testing of drug-involved pregnant women that I detail below, or "suspicionless" drug testing in schools. While appearing "universal" or random, in reality these programs target certain, highly gendered and racialized populations of persons perceived to be drug users. Technologies of suspicion continue to be used coercively on populations constructed as incapable of self-governance, while other, more privileged groups are addressed as actively governing themselves. There are no more paradigmatically "untrustworthy" subjects than drug users, whose addicted state is widely portrayed as a "state of alienation from truth" that may infect others if unchecked (Campbell 2000, 49; Keane 2002, 31).

Drug tests provide a forensic means of verifying the truth-claims of those suspected of illicit drug use. The scientific basis underlying urine testing, the most widely accepted form of drug testing, was well established by the 1970s in the context of widespread drug use among Vietnam veterans. Researchers who established the scientific basis of testing assumed that tests would largely be deployed in therapeutic contexts, and that increased knowledge about the validity of testing methods "is basic to the intelligent use of urine screening and the interpretation of the results" (Gorodetzky, et al. 1974). However, the U.S. military turned to testing not only to screen and refer veterans to treatment but because testing-and the threat of testing--was assumed to bring about desirable behavioral change. This stance was later extended to 
arguments concerning the increase of productivity among American workers; and finally to health care delivery and educational settings. While the social and economic benefits of testing were widely debated in the early 1980s, institutionalization has rendered them less controversial if not less costly. Each introduction of a novel testing modality has been accompanied by some popular concern about how the tests are deployed, what consequences accrue to "positive" results, and whether the tests are reliable, valid, and accurate. In the 1980s approximately one quarter of Fortune 500 companies began drug screening in hiring. The testing industry itself had swelled to a $\$ 2$ billion per year enterprise by the mid-1980s (Hoffman and Silvers 1987).

Ronald Reagan's 1986 Executive Order 12564 required federal agencies to urine test in the effort to guarantee a "drug-free federal workplace." Testing became commonplace first in federally regulated U.S. workplaces and educational institutions, and then to large, private sector organizations (ACLU 1999). When the American Management Association (AMA) first surveyed its members' corporate drug policies in 1987, only 21 percent had testing programs. Despite the expense of testing that figure rose to 81 percent of major U.S. firms by 1996 (ACLU 1999). Today more than 500 school districts in the United States have testing programs. When home tests were first offered for private sale to parents, Psychemedics, the company offering hair analysis kits, experienced stock surges (Hirsch 1993). Kits are readily available on the Internet - as are products designed to "tamper" with results. Founded in 1995, the Drug and Alcohol Testing Industry Association (DATIA) seeks to expand the testing market and lobby for over one thousand member organizations. As the twentieth century ended, Standard and Poors estimated the size of the entire U.S. drug and alcohol testing industry at $\$ 5.9$ billion per year.

Workers in large organizations, the public sector, and specific occupational categories are most likely to be tested, and the consequences of a positive test vary from referral to treatment often in the form of Employee Assistance Programs (EAPs) to getting suspended, fired, demoted, or most commonly not hired. Data on the effects of drug use upon worker productivity, absences, turnover, injuries, and accidents remain equivocal, but it is fair to say that occupational injury directly due to drug use is negligible compared to that from exposure to workplace toxins, accidents not caused by drug and alcohol use, or employer negligence. This article mainly concerns drug testing in "caring" institutions; elsewhere I consider its use in criminal (in)justice contexts and the administration of social and human services (Campbell, forthcoming).

\section{Love, Care, and Trust Enabling the Post-disciplinary World of Surveillance}

Two interrelated questions facing the new surveillance studies are the extent to which panoptical surveillance can be valenced towards "benign" or beneficial effects or exercised in service of compassion, and the possible place of resistance in situations of pervasive surveillance (Sewell, 1995: 11). David Lyon argues for the social ordering capacity of some forms of surveillance, as well as a reevaluation of the "place of love, care, trust, and enabling within the surveillance system" (Lyon, 1993: 675). Arguing for the historical and cultural specificity of forms of "care," Vaz and Bruno (2003) state that "our form of caring may also be a way of not comprehending others." The historical and conceptual limitations inculcated by current "ways of caring"especially where "others" are concerned--cannot be dissociated from current modes of subject 
formation that follow from how technologies of suspicion are deployed within systems of surveillance. Within the context of health care delivery, social welfare, and child protection, upon first reflection there might seem to be a place for "caring surveillance." Ultimately, it is difficult if not impossible to maintain that such systems are benign or compassionate.

An illustrative case was provided by the Medical University of South Carolina (MUSC) program that I consider below. The MUSC program was jointly initiated by obstetrical nursing staff and law enforcement, who administered toxicology screens to pregnant women with the ostensible purpose of getting addicted women into treatment. Drug tests were performed without the women's knowledge or consent, in the course of prenatal care, and justified on grounds of concern for them and their children. The vast majority were performed on women of color living in circumstances of extreme economic disadvantage. The uneven availability of privacy rights to low-income women, who are disproportionately women of color in the United States, works against the claim that such surveillance can be "benign," even where it is supposedly health- or productivity-enhancing. Female drug users are constructed as threatening not only themselves but their children: "we may think of them as putting others at risk because they are careless with themselves" (Vaz and Bruno, 2003: 288). The very definition of addiction as a chronic, relapsing, compulsive disease in which needs for the drug subsume or override all other needs contributes to the idea that drug use is antithetical to care for the self and others. Those who cannot care for themselves are not fit to care for others, and themselves require a "coercive compassion," in this instance, the covert administration of a drug test that entailed legal penalties.

The technical practice of drug testing-both development and deployment of testing technology — has preceded science, policy, and wide social debate in the social domain of illicit drug testing. "We regard drug testing as an area in which practice has preceded science," noted Reid at al. (1990), who argued that testing programs should consider the psychological effects of testing on incumbent and prospective employees' attitudes and behaviors. Both proponents and critics of testing acknowledge that the tests have been deployed prior to full consideration of their implications. Practical systems operate according to immanent logics and group norms that shape how actors conduct themselves within social structures and macro-media they can only partially discern. Scholars in science and technology studies (STS) - a useful interdisciplinary inquiry for those in surveillance studies--grapple better with the set of practices, logics, and norms that are condensed or embedded in a technology than they do with the social structures and macro-media in which technologies are situated (Klein and Kleinman 2002). The analytical trick is distinguishing which macro-structural contexts bear practically upon the everyday tactics and strategies that comprise systems of "embodied practice." In the drug-testing arena, a contextual state of domination also renders strategies of "reversal" unviable (Sewell, 1995: 10). On this question, I turn to the Archaeology of Knowledge, in which Foucault advocated detailed study of "practical systems," interlinked forms of political rationality that organize activity, strategy, and technology in relatively "homogenous" ways. Practical systems are interlinked systems of relations or connections between the control of things; actions upon others (which Foucault would later call governmentality or the "conduct of conduct"); and relations with oneself. Drug testing regimes are designed to monitor, verify, and regulate the "conduct of conduct" - the effect of their deployment is a climate of suspicion. 
Foucault's three axes of knowledge, power, and ethics interconnect to contribute coherence and a sense of systematicity to his analysis of power, which operates at three levels: "[games of] strategic relations, techniques of governance, and states of domination" (Foucault, 1994: 299). The second or mediating level, techniques of governance, encompasses the deployment of techniques used to establish or maintain "state[s] of domination," situations in which one group strategically blocks, freezes, or otherwise immobilizes power relations so as to prevent reversible movement and unilaterally constrain the practices of freedom" (Foucault, 1994: 283; emphasis mine). Drug-testing technology provides an example of a technological device that is used to block, freeze, or otherwise immobilize power relations within the "practical systems" of its domain. Technological surveillance techniques are examples of a type of domination that is less reversible in the sense that resistance is effectively foreclosed by pervasive technologies deployed as techniques of governance. That is partly why such technologies of suspicion are attractive to a military industrial complex bent on regulating if not entirely controlling a wide spectrum of behaviors. Analysis of such techniques requires systematic engagement with states of domination and the specific economy of suspicion and coercion that prevails in "caring" institutions. Technologies of suspicion are often coercively deployed in the name of compassion.

\section{Coercive compassion, compassionate coercion}

One of the most egregious deployments of drug-testing took place in Charleston, South Carolina, at the height of concern about maternal crack-cocaine use (Campbell, 2000: 169192). The MUSC program administered urine tests for cocaine metabolites to pregnant women without their knowledge or consent, and reported the results to law enforcement. Ostensibly motivated by beneficent purposes, Nurse Shirley Brown, the obstetrical case manager for MUSC, cooperated with Charleston solicitor Charles Condon (soon to become State Attorney General) in designing and implementing a program to "facilitate treatment and protect both the mother and the unborn child" (Ferguson v. Charleston, 2001: 2, 6). The program led to the arrest of over thirty women, all but one women of color, before court challenges ended it. The health care workers, prosecutors, and law enforcement officials involved in crafting the program used "deceptive strategies" to coerce pregnant women to "freely" give urine samples such as stating the tests were for dehydration (Center for Reproductive Rights, 2002). Yet the protocol made no mention of change in prenatal or antenatal care should the test results come back positive. The results for individual women tested were far from benign or beneficial.

Women's advocates cast those involved in crafting and implementing the policy as uncaring and racist in practice and belief. The central feature of the policy was the supposed use of drug test results to coerce patients into substance abuse treatment-yet no treatment programs operated at that time in South Carolina that accepted pregnant women. Because the immediate objective of the testing program was to generate evidence "for the specific purpose of incriminating those patients," the Court insisted that health care workers were obligated to fully inform patients of their constitutional rights prior to testing. On "Nightline," Lynn Paltrow, founder of the National Advocates for Pregnant Women (NAPW) cast the staff as "medical vigilantes," while attorney Susan Dunn argued, "It's un-American, an abuse of power, coercion and control, that turns doctors into tools of the state" (Nightline). Condon, on the other hand, claimed the "damage [to 
the fetus] is already done, so we'll treat this as a crime" (Nightline). These representations set up the continuum between "benign" surveillance and what I have called a regime of "coercive compassion."

Ultimately, the U.S. Supreme Court found that such testing programs violate Fourth Amendment protections against unreasonable search and seizure if their purpose is to alert police that a crime has been committed (Ferguson v. City of Charleston 2001; Greenhouse, 2001: A1). The tests were warrantless and nonconsensual searches administered according to criteria that correlated with poverty, malnutrition, and lack of access to the health care system, such as getting incomplete, late, or no prenatal care; preterm labor; or intrauterine growth retardation (Ferguson v. City of Charleston, 2001: 4). The issue before the Court was whether or not the "special needs doctrine," a closely guarded exception to the Fourth Amendment applied in limited circumstances to justify drug testing of custom agents, railroad workers involved in train accidents, and student athletes, could be widened in scope. Given the extreme incursion into pregnant women's privacy rights by the City of Charleston in this case, the Court ruled that it did not apply.

The policy left little room for love, care, or trust. Toxicology screens administered as part of health care delivery differ in their effects from those administered in criminal justice settings. Women were deterred from seeking obstetrical care, leading to documented increases in the numbers of abandoned infants, as well as increasing the level of generalized distrust of medical and legal authority that arises from such abuses of civil and human rights among subjected populations. Distrust might seem to offer a source of collective resistance for women who bore the brunt of this policy. Powerful allies were brought in by the women's advocates - not one amicus brief was filed on behalf of the City of Charleston, while dozens of organizations ranging from organized medicine to social workers to drug policy reform and civil liberties advocates filed for the plaintiffs. While affected individuals can now seek damages in the wake of the U.S. Supreme Court's 2003 refusal to rehear the case, collective resistance was dampened by the relative social isolation of impoverished, drug-using women and the difficulty of constructing cross-class and cross-race alliances on drug issues (Paltrow 2001). However, the case enabled resistance in the form of an emerging feminist analysis of the unique convergence between heightened scrutiny of the reproductive processes of low-income women of color and the specific effects of the deployment of surveillance technologies upon them. The feminist resistance was possible only after the policy took its toll upon a vulnerable population.

\section{Analyzing Forms of Powerat Play in Drug Control Culture}

Drug policy devolves to the stark question of who uses what when, where, and how - and as long as drug policy is predicated upon a largely fictional ideal of abstinence, forensic techniques for verifying measurable divergence from that state will be sought. Since the 1970s drug policy has assumed the technological capacities to arrest, predict, and so prevent drug-using behavior that government and industry consider socially problematic, a term used to signal contextspecific understanding that the widespread social problematization of drug use and "deviant" 
behavior varies over time and space. All societies tolerate some forms of drug use and discourage others. While technologies of suspicion are often deployed in ways that seem arbitrary and capricious to their subjects, they constitute and police populations systematically.

Concerns expressed by communities of color about policing practices - "Driving While Black (DWB)" "racial profiling," or the corresponding lack of drug enforcement in white communities despite rates of use as high or higher than those among people of color - name an awareness of the systematicity of distrust. The "populations" constituted through technologies of suspicion are multifarious, their boundaries blurred by affiliations across demographic groups and their coherence riddled with "non" members, or momentary members as the case may be. However, the fact remains that women of color are drug-tested at a far higher rate than white women in medical settings even in situations where white women are as likely to use illicit drugs (Chasnoff, 1990: 1202). The drug use habits of the poor-who are more likely to seek medical care in public settings - are simply more open to scrutiny and thus less protected from the technologies that locate each of us within social routines that build or erode trust. The unarguably material forces of a "drug control culture" are directed towards regulating populations and disciplining bodies through an "array of surveillance mechanisms, policing techniques, and normalizing procedures" (Reeves and Campbell, 1994: 25).

Routinely, hope surfaces that drug research and technoscientific innovations based upon it will develop to "direct" a scientifically rational drug control policy. Yet drug control policy—at least that of individual demand reduction--is about the desire to achieve and reproduce certain qualities of citizenship deemed necessary for governability at a time when it is no longer docile bodies but active citizens that are the desired end products (Rose, 1999). The constitution of certain populations as "ungovernable" arises where "the other" is represented as failing to handle freedom properly. Governability occurs at the interface between techniques used to dominate others and technologies that enable the construction of self-control and productivity within the prevailing governing mentalities (Campbell, 1995: 80-81). Foucault used "policing" broadly to encompass how military, penal, familial, and welfarist institutions "integrate individuals into the state's utility" (1988: 153). Governments worry about individuals who are poorly integrated "insofar as they are somehow relevant for the reinforcement of the state's strength: what they do, their life, their death, their activity, their individual behavior, their work, and so on" (1988: 152). The "troubled individual" - and especially the so-called hard case-stands at the convergence between the "tutelary complex" and the "carceral society" in the hte Foucault's thought. A suggestive link emerges between tutelage regarding consumption practices and incarceration.

That link forms the basis of a technocratic science of "troubled individuals" - and the rationalization of state and corporate responses to their troubles through discipline and punishment - that has flourished in drug control culture. One of my subsidiary purposes in preparing this essay was to further bridge interdisciplinary science and technology studies (STS) and surveillance studies. The conceptual approaches of STS alert us to the social construction of technological artifacts in power-differentiated arenas. Sociology of science approaches the social organization of trust and distrust and the social construction of credibility as the social basis upon which scientific knowledge claims are produced (Epstein, 1996: 14-17). Secondly, STS practitioners empirically document the extensive variety of social contexts in which technologies are deployed - and by contexts I mean social, historical, and culturally specific aspects that 
shape how people attribute meaning to technologies. Feminist analysis renders visible the differential effects that drug-testing had in the MUSC case. These effects will vary depending on which settings, target populations, and substances are scrutinized. Surveillance-and the characteristics of power that undergird it--look different depending on whether one analyzes people who are relatively integrated or relatively excluded from the utilities of state and market, or at the criminal justice, social welfare, or health care settings. Coercive and compassionate powers are particularly difficult to differentiate where the health and welfare of vulnerable populations is at stake. Finally, surveillance technologies contribute to the social construction of "target populations" that characterize policy regimes that exercise differential effects upon their intended target populations (Schneider and Ingram, 1997). Public policy conveys messages about the relative worthiness of particular social groups as well as allocating the benefits and burdens of membership in a citizenship category.

Individual members' relative vulnerability to or insulation from the impact of surveillance is one of the characteristic dimensions along which socially constructed "target populations" can be differentiated. Members of advantaged groups-including most middle-class professionals--are often buffered from the intense scrutiny their less advantaged counterparts receive. Certain classes of workers (for instance, college faculty or administrators) are rarely subjected to testing or its consequences. Surveillance - and the sense of heightened vulnerability to scrutiny that accompanies it--is lived at the level of individual experience, even in the case of membership in the "suspect" classes.

\section{The Multiplic ity of Individuals in the Laboratory of Power}

Continuous individual supervision was the first of three aspects of panopticism that Foucault identified as characteristic traits of disciplinary society. The functions of supervision, control, and correction subsumed the individual: "In panopticism, the supervision of individuals is carried not at the level of what one does but of what one is, not at the level of what one does but of what one might do. With this system, supervision tends increasingly to individualize the author of the act" $(1994,71)$. The increasing pervasiveness of drug-testing has widened the net- the majority of the U.S. working population has now experienced testing. The ontology of surveillance reaches beyond individuals to constitute social categories or "target populations": "It was the structure of supervision which, drawing individuals to it, taking hold of them individually, incorporating them, would constitute them secondarily as a group" (1994, 77). The social category "drug addicts" is produced by assuming the supposed predictive value of drug tests"not at the level of what one does but of what one might do" (Foucault 1994, 71). While this aspect of supervisory power- "not at the level of what one does but of what one might do"does individualize, technologies of suspicion convert the tactic of individualization into a more generalized targeting that constitutes population groups on the basis not of what they actually do, but on the basis of what they might do.

One under-interpreted aspect of Foucault is his evocative comparison of the Panopticon to Le Vaux's menagerie at Versailles, which was patterned to individualize observation in ways that became central to human and animal experimentation (Foucault, 1979: 203). Such spatial 
arrangements facilitated increased access to individuals constituted as subjects of social and medical experiments, opening up ways to constitute and transform populations based upon categories of behavior, social location, and relations between the two. "The Panopticon is a privileged place for experiments on men, and for analyzing with complete certainty the transformations that may be obtained from them. The Panopticon may even provide an apparatus for supervising its own mechanisms" (Foucault, 1979: 204). This "self-supervising" capacity is now augmented by forensic techniques assumed somehow to deter unwanted behaviors and promote desirable ones. MUSC's covertly administered toxicology screens were somehow supposed to discourage illicit drug use by pregnant women yet encourage them to present for health care. Functioning as a "laboratory of power," the Panopticon figured as a political technology detached from any specific use and thus "polyvalent in its applications" (Foucault, 1979: 205). The panoptic schema could perform a range of diagnostic, therapeutic, and administrative functions, but chief among its uses was the capacity to augment or amplify power (Foucault, 1979: 205, 207). Drug-testing in schools and the workplace is not simply about individual behavior but about institutional compliance with federal "drug-free workplace" requirements and conditional federal aid. Power accrues to the institution within which individuals are supervised and transformed, but the institutions themselves fall under reporting requirements. The MUSC experiment to transform pregnant, drug-using women from "dirty urines" to "clean" relied upon a simple urine test, the powers of which were significantly augmented in the health care delivery setting by hierarchical availability of information about the test, its results, and the consequences meted out on the basis of the results. To diagram what power looked like in this situation would require acknowledging the convergence of multiple levels and types of surveillance, distrust, and reinforcement and amplification of local cultural representations.

Foucault extended the Benthamite Panopticon to a "generalizable model of functioning" with the goal of diagramming a "mechanism of power reduced to its ideal form" (Foucault, 1979: 205). The diagram was fluid and unstable: "[The diagram] never functions to represent a persisting world but produces a new kind of reality, a new model of truth. It is neither the subject of history, nor does it survey history. It makes history by unmasking preceding realities and significations, constituting hundreds of points of emergence or creativity, unexpected conjunctions or improbable continuums. It doubles history with a sense of continual evolution" (Deleuze 1988, 35). The diagram maps the relations of force between strategies and practicesone of which was law, the "integration of illegalisms" (Deleuze 1988, 37). It is crucial to see that the diagrammatic Panopticon works not through homogenization, the production of conformity, but through an integration of individual differentiation. The Panopticon is a machine for ordering multiplicity that works in the domain of "irregular bodies, with their details, their multiple movements, their heterogeneous forces, their spatial relations" (Foucault 1979, 208). To constitute this political anatomy, what is required are "mechanisms that analyze distributions, gaps, series, combinations, and which use instruments that render visible, record, differentiate and compare; a physics of a relational and multiple power, which has its maximum intensity not in the person of the king, but in the bodies that can be individualized by these relations" (Foucault, 1979: 208). Bio-assays such as drug tests serve as instruments that provide a forensics of individual consumption practices now common in workplaces, health care and social service delivery settings, as well as the criminal justice system. 
Whether deployed within therapeutic or criminalizing systems, drug-testing is part of a datadriven apparatus for disciplining populations that has spread rapidly in the United States, although more slowly elsewhere. The spread of privileged enclaves of discipline was the most evident symptom that disciplinary regimes had achieved the status of a "general formula" (Foucault, 1979: 209). Foucault noted three processes undergirding discipline's generalization that are relevant to the question of whether the Benthamite physics of power remains in play in a post-disciplinary society. These processes are analogous to processes at work in our own era. The first of these, the "functional inversion of the disciplines," is directly relevant to drug-testing. "Inversion" captured the positive aspects of discipline at work in producing "productive citizens" and workers: "The disciplines function increasingly as techniques for making useful individuals" (Foucault, 1979: 211). They also detect and categorize individuals considered "disposable" or unwanted, those whose participation in criminal activity or compromised workplace productivity render their utility questionable (ACLU September 1999). Secondly, the "swarming" and diffusion of disciplinary mechanisms through case-work and other forms of observation characterize post-disciplinary mechanisms (Foucault, 1979: 212; Lunbeck 1994; Tice 1998). Thirdly, and perhaps most importantly for the future, state control of disciplinary mechanisms has a complement in our time of neoliberal divestment in state functions-especially policing - that diffuse into and become coextensive with the private and corporate sectors, in which innovative surveillance technologies ranging from continuous satellite monitoring of sweat patch data to electronic bracelets or implants proliferate like speculative fictions. These will allow the achievement of even more seamless coextensivity between institutional and environmental panopticism. Lastly, there has been a shift away from scopic panopticism and towards the surveillance of previously internal processes such as drug consumption.

Like the shift Foucault describes between the enclaved or quarantined spaces of the "plague city" and the "indefinitely generalizable mechanism of 'panopticism'," biological assays must be contextualized within the context of their generalization. They are administered within regimes that are little differentiated from the historical conjuncture Foucault describes in his section on Panopticism, where the tactics of disciplinary power meet three criteria:

1. power is exercised at the lowest economic cost possible, and arouses little resistance because of its relative discretion and invisibility;

2. power is exercised through intensification and extension;

3. power is used to augment both the docility and utility of the individuals who comprise the system (Foucault, 1979: 218).

There is one crucial difference unique to post-sovereign, post-disciplinary society. The emerging emphasis on active citizenship, on the "activation" or "animation" of individual responsibility rather than on the production of docile subjects is a central tenet of neoliberal or "advanced liberal" regimes (Rose, 1999). Utility has been redefined, for discipline is no longer the "unitary technique by which the body is reduced as a political force at the least cost and maximized as a useful force" (Foucault, 1979: 221). The need of liberal capitalist democracies for "active" and "productive" consumer-citizens culminates in a focus on consumption patterns. No longer production but consumption has become paramount in the integration of the individual citizen into the state's utility. Surveillance of consumption--long a concern of the modern state-has become 
an activity of enormous scope. Drugs serve as the paradigmatic example of what one ought not to consume if one wants to remain a productive citizen.

\section{The Crisis of Divergent Desires and the Commercialization of Suspicion}

The new social movements (NSMs) of the 1960s and 1970s, including post-colonial independence movements, brought to crisis the social contracts through which individuals are "integrated into the state's utility," and delegitimated some of the forms of control, command, and authority once central to modern disciplinary regimes. Concretely posed, the problem became how to govern in a post-disciplinary world - as Michael Hardt and Antonio Negri put it in Empire, "a new form of control had to be posed in order to establish command over what was no longer controllable in disciplinary terms" (256). They argue that the structural and cultural crises that unsettled the post-World War II settlements opened two social control strategies for capital. The first were repressive strategies aimed at disaggregating the labor market, privileging certain workers and marginalizing others (Hardt and Negri 2000: 267). Repressive strategies are clearly discernible in workplace drug-testing programs, which sort "good" workers from "bad" ones. "The repressive use of technology, including the automation and computerization of production, was a central weapon wielded in this effort" (Hardt and Negri 267). However, it is a mistake to restrict the repressive possibilities to production when what was really at stake was how social reproduction took place. More "positive" paths for capital's response become evident when we look at non-workers and the impact of technological transformations aimed at "changing the very composition of the proletariat." Labor struggles through which workers recognize themselves as rights-bearing are salient to questions of workers' willingness to accept the deployment of the technologies of suspicion and surveillance that undergird the institutionalization of distrust. As David Lyon has pointed out, "disciplinary networks do connect employment with civil status or consumption with policing" (Lyon, 1993: 667).

Leisure time, i.e. what workers do off the job, how "non-workers" spend their time, and how youth--not-yet workers--conduct themselves has long been the object of suspicion and scrutiny. Foucault devoted a lecture series in Rio de Janeiro to the transformations of time and body required by capital (1994: 80-83). In "Americanism and Fordism," Gramsci pointed to employer concerns with alcohol use and sexual relations. Ongoing debates over "bad habits" and time ill spent came to a head simultaneously with the rights struggles of the NSMs. The more countercultural NSMs focused not only on drugs, but on dietary regimes and other matters of personal hygiene. Anxiety about licit and illicit consumption continues to be central to the bodily experience of late-stage consumer capitalism (Brennan, 2003). The development of bodily policing techniques is not surprising given the way in which drugs came to figure illegitimate desires and thus potential sources of internal subversion, inverted values, and invisible yet detectable bodily alteration. The century-long preoccupation with identifying physical markers of deviance including drug addiction and assembling tables of attributes that separate drug addicts from non-addicts has now culminated in the compiling of databases of tattoos, scars, and other physical markers of "gang" activity for use by law enforcement. Today's obsession with "marking" and verifying deviance through forensic techniques contrasts to the domestic Cold War paranoia of the unmarked and thus unknowable "enemies within" (Campbell 2000). 
Social struggle marked the point where "the disciplinary regime clearly no longer succeeded in containing the needs and desires of young people," where the normalization of worker discipline was figured as no longer affording life but death (Hardt and Negri, 2000: 273-274). Contestation and cultural experimentation resulted; "drugs" became a condensed signature for representing multiple countercultures and the ranks of the undisciplined. The development and deployment of technologies designed to detect drug use and to measure the quantitative effects of drug use upon worker productivity arose out of the impulse to reassert authority and discipline within the workplace, out of employers' perceived loss of control over "their" workforce. Similarly, the concerns of cultural conservatives that their authority was being challenged called for the reassertion of paternalistic policies and so-called compassionate conservatism.

Foucault correctly predicted that the mechanisms through which command and control take place would be more "democratic," dispersed, "distributed through brains and bodies" in ways that increasingly interiorize behaviors of social inclusion and exclusion within subjects (1979: 207; Hardt and Negri, 2000: 23). The processes of "post-normalization" now at work are characterized by the intensification and generalization of normalizing apparatuses through a new mode of control that extends outside or beyond the structured sites of institutions. This raises the question of the extent to which the "total institutions" of disciplinary society can be said to ever have entirely consumed individuals versus the extent to which this intensified version of postnormalization pervasively permeates and systematically organizes individual activity.

Drug testing offers a symptomatic arena in which biopolitics and the panoptic arrangement of organizational and governmental responses converge upon individual practices of consumption. As Lyon points out, consumerism is the main means of social integration and participation in a consumer democracy. Not everyone lives in a "post-disciplinary" world. "Flawed" consumers experience old-fashioned, panoptic discipline, and "the norms from which they deviate are rooted in consumer skills" (Lyon, 1993, 671). We must also consider what to make of the other end of consumption--the innovation, production, and distribution of testing technologies by commercial concerns - in light of the form of sovereignty that Foucault called "governmentality" that emerged in the wake of disciplinary regimes. Attempting to introduce multiplicity into this emergent formulation, I use the term "governing mentalities" (Campbell, 2000). While the division between state, economy, and civil society was central to discipline, these divisions declined in salience when discipline gave way to the less-differentiated networks of the "society of control," Hardt and Negri's apt term for it. As they sum up Foucault's argument, discipline worked as an "inner compulsion indistinguishable from our will, immanent to and inseparable from our subjectivity itself' (329). The institutions through which discipline is exercised, however, set the enabling constraints according to their logics, dividing up social space and, I would add, subjective labor. The Panopticon is a metaphor for this activity of division and individual differentiation so essential to disciplinary regimes, and a model that suggests the logics of power at work within it.

The social and psychic transitions that led to the "society of control" and drug-control culture did not mean that discipline gave way but that it coextended laterally and merged with forms of postdisciplinary power. Technologies and strategies of control have shifted. I do not mean to make 
too much of our willingness to pee in a cup. But the production of subjectivities along the lines of those required by capital has become evident in the accumulation of the millions of insignificant acts that signify assent to the pervasiveness and even the necessity of post-disciplinary surveillance. The commercialization of suspicion-marked by the extent to which electronic and forensic techniques have been integrated into work, school, and domestic relations-has moved technologies of suspicion into the practices of everyday life.

Bio-assays and personal electronic technologies simultaneously diffuse and individualize surveillance. They also "facilitate convergence of practices over diffuse and once distinct institutional areas" (Lyon, 1993: 666). For instance, the potent conjunction of information technology (IT) with bodily surveillance technologies facilitates the convergence between workplace regulation and the regulation of consumption and other leisure activities through diverse information architectures ranging from databases to track so-called welfare fraud, gang formation, and tax evasion to the practice of digital "fingerprinting" as a routine part of social provision. Such forms of information extraction are unevenly applied to individuals who are not seen as "integrated into the state's utility" (Eubanks 2002: 1-3). These techniques rest upon a set of exclusionary policies and presumptions based upon the interpretation of "information" generated through testing technologies. Within the gendered and racialized states of domination we currently inhabit, it is highly unlikely that such practices of surveillance can ever be socially just.

\section{References}

American Civil Liberties Union. (1999) Drug Testing: A Bad Investment. New York: ACLU.

Brennan, T. (2003) Globalization and Its Terrors: Daily Life in the West. New York: Routledge.

Campbell, N. D. (Forthcoming 2004) Suspect Technologies: Scrutinizing the Intersection of Science, Technology, and Policy, Science, Technology, and Human Values. 29(4).

Campbell, N. D. (2000) Using Women: Gender, Drug Policy, and Social Justice. New York: Routledge.

Carey, C. A. (1998) Crafting a Challenge to the Practice of Drug Testing Welfare Recipients, Buffalo Law Review. 46: 285-345.

Center for Reproductive Rights (2002) Court Upholds Rights of Pregnant Women: Medical University of South Carolina Drug Testing Scheme Found Unconstitutional. http://www.reproductiverights.org Accessed 19 January 2003.

Chasnoff, I. (1990) The Prevalence of Illicit-Drug or Alcohol Use During Pregnancy and Discrepancies in Mandatory Reporting in Pinellas County, Florida, New England Journal of Medicine 322(17): 12021206.

Cropanzano, R. and M.A. Konovsky (1993) Justice Considerations in Employee Drug Testing. In R. Cropanzano (ed.) Justice in the Workplace: Approaching Fairness in Human Resource Management. Hillsdale, NJ: Lawrence Erlbaum, 207-257.

Currie, E. (1993) Reckoning: Drugs, the Cities, and the American Future. New York: Hill and Wang.

Deleuze, G. (1986) Foucault (trans. S. Hand). Minneapolis, MN: University of Minnesota Press. 
Epstein, S. (1996) Impure Science: AIDS, Activism, and the Politics of Knowledge. Berkeley, CA: University of California Press.

Eubanks, V. (2002) Unpublished dissertation proposal. Rensselaer Polytechnic Institute.

Foucault, M. (1979) Discipline and Punish: The Birth of the Prison (trans. A. Sheridan). New York: Vintage Books.

Foucault, M. (1988) The Political Technology of Individuals.In L. H. Martin, Gutman, and Hutton (eds.) Technologies of the Self. Amherst, MA: University of Massachusetts Press, 147-162.

Foucault, M. (1994) The Ethics of Concern for the Self as a Practice of Freedom. In P. Rabinow (ed.) Essential Works of Michel Foucault, 1954-1984. v.1 (trans. Robert Hurley and others ). New York: The New Press, 281-330.

Foucault, M. (2000) Truth and Juridical Forms. In J.D. Faubion (ed.) Essential Works of Michel Foucault, 1954-1984. v.3 (trans. R. Hurley and others ). New York: The New Press, 1-89.

Gilbert, N. (2002) Transformation of the Welfare State: The Silent Surrender of Public Responsibility. Oxford: Oxford University Press.

Gorodetzky, C. W., C. R. Angel, D. J. Beach, D. H. Catlin, and S. Yeh (1974) Validity of screening methods for drugs of abuse in biological fluids: I. Heroin in urine, Clinical Pharmacology and Therapeutics, 15(5): 461-472.

Grant, B. F. and D. A. Dawson (1996) Alcohol and Drug Use, Abuse, and Dependence among Welfare Recipients, American Journal of Public Health. 86(10): 1450-1454.

Greenhouse, L. (2001) High Court Bars Some Drug Tests, New York Times 22 March.

Hardt, M. and A. Negri (2000) Empire. Cambridge, MA: Harvard University Press.

Hirsch, J. S. (1995) Psychemedics Stock Surges 71\% on News of Private Drug Test, Wall Street Journal 13 July, B7.

Hoffman, A. and J. Silvers (1987) Steal This Urine Test: Fighting Drug Hysteria in America. New York; Penguin Books.

Keane, H. (2002) What's Wrong with Addiction? New York: New York University Press.

Klein, H.K., and D.L. Kleinman (2002) The Social Construction of Technology: Structural Considerations, Science, Technology, and Human Values 27(1):

Lyon, D. (1993) An Electronic Panopticon? A Sociological Critique of Surveillance Theory, Sociological Review, 41: 653-678.

Lyon, D. (1994) The Electronic Eye: The Rise of Surveillance Society. Oxford: Polity Press.

McFadden, C. (2000) 'How Far Can You Go to Protect an Unborn Child? Pregnant Women Arrested for Using Drugs.' Nightline, ABC News. September 27, 2000.

Paltrow, L. M. (2001) The War on Drugs and the War on Abortion. Southern University Law Review, 28(3): 201-253.

Reeves, J. L. and R. Campbell (1994) Cracked Coverage: Television News, the Anti-cocaine Crusade, and the Reagan Legacy, Durham, NC: Duke University Press. 
Schneider, A.L. and H. M. Ingram (1997) Policy Design for Democracy. Lawrence, KS: University of Kansas Press.

Sewell, G. (1995) On the Possibility of a Sociology of Workplace Surveillance. Paper given at the American Sociological Association Annual Meeting. Chicago, IL. 26 November.

Shapin, S. (1994) A Social History of Truth: Civility and Science in Seventeenth Century England. Chicago: University of Chicago Press.

U.S. Supreme Court. Ferguson v. City of Charleston (2001) 99-936.

Vaz, P. and F. Bruno (2003) Types of Self-Surveillance: From Abnormality to Individuals 'at Risk' Surveillance and Society, 1(3): 272-291.

http://www.surveillance-and-society.org/articles1(3)/self.pdf 